\section{ECCOMAS}

\section{Proceedia}

COMPDYN 2021

$8^{\text {th }}$ ECCOMAS Thematic Conference on Computational Methods in Structural Dynamics and Earthquake Engineering M. Papadrakakis, M. Fragiadakis (eds.) Streamed from Athens, Greece, 28 - 30 June 2021

\title{
SUPPLEMENTAL ENERGY DISSIPATION WITH PRESTRESSED LEAD EXTRUSION DAMPERS (P-LED): EXPERIMENTS AND MODELING
}

\author{
C. Pettorruso ${ }^{1 *}$, E. Bruschi ${ }^{1}$, V. Quaglini ${ }^{1}$ \\ ${ }^{1}$ Politecnico di Milano, Department of Architecture, Built Environment and Construction Engineering, \\ Piazza Leonardo da Vinci 32, 20133 Milan, Italy \\ e-mail: \{ carlo.pettorruso, eleonora.bruschi, virginio.quaglini \}@polimi.it
}

\begin{abstract}
Supplemental energy dissipation devices are employed both in new and retrofitted constructions in order to prevent structural damage, increase life-safety and achieve a desired level of performance. Among these devices, hysteretic dampers have been proven to be an appropriate and economically affordable solution to reduce the vulnerability of ordinary structures, such as residential, school and industrial buildings. The study presents an experimental and numerical investigation of a Prestressed Lead Extrusion Damper (P-LED), an emerging energy dissipation device which provides energy dissipation by means of the plastic extrusion of lead through an orifice created between a containing tube and a moving shaft and achieves high specific output force by preloading of the working material.

The experimental investigation is performed following the provisions set in the European standard EN 15129 for Displacement Dependent Devices. A damper prototype is tested in cyclic tests at different displacement amplitudes and in a monotonic ramp up to the amplified design deformation. The damper shows a rigid-plastic behavior, without strength degradation regardless of the imposed deflection; the shape of the hysteresis loops is essentially rectangular, resulting in an effective damping of 0.55 , very close to the maximum theoretical level; the device is able to sustain multiple cycles of motion at the basic design earthquake displacement, anticipating a maintenance-free operation even in presence of repeated ground shakes. A $3 D$ finite element model of the P-LED is formulated in Abaqus and validated upon the results of the experimental tests. The model enlightens that the output force of the damper accounts for two contributions, namely the extrusion force of the lead and the friction force between the lead and the moving shaft. The model is then used in a parametric study to investigate the influence of the device dimensions, namely the diameters of the shaft, of the containing tube and of the bulge, and the length of the shaft, on the output force. The numerical data points are fitted by a simple model which can be used for design of the damper to a specific quasi-static force.
\end{abstract}

Keywords: Lead Extrusion Damper, EN 15129, energy dissipation, experimental assessment, finite element model. 


\section{INTRODUCTION}

Supplemental energy dissipation is employed both in new and retrofitted constructions in order to prevent structural damage, increase life-safety and achieve a desired level of performance ([1],[2]), appearing an appropriate and economically affordable solution to reduce the vulnerability of ordinary structures, such as residential, school and industrial buildings [3]-[6].

Current energy dissipation devices can be classified in two main categories [7]: (i) the socalled fluid viscous dampers, where the dissipation is achieved through the lamination of a viscous fluid forced by a piston to pass through an orifice or a valving system, and whose behavior strictly depends on the fluid velocity; (ii) the hysteretic dampers, which are further classified in hysteretic steel dampers, friction dampers and metal extrusion dampers, depending on the mechanism actually used to dissipate the seismic energy.

Most of the dampers used in residential, school and industrial buildings belong to the hysteretic damper's category ([2],[4],[6],[8] and [9]), whose constitutive law mainly depends on the displacement.

Supplemental energy dissipation is typically implemented by providing the structure with dissipative bracing systems, made of steel braces incorporating dissipation devices [10]. This approach is aimed at achieving two effects, namely increase the structural stiffness, which reduces the structural displacement, and dissipate much of the seismic energy, which reduces the structural acceleration [11].

However, though in principle dissipative braces represent a viable solution to protect any kind of building, they show some drawbacks such as increased internal forces in beams and columns, modification of the building layout, and in case of retrofit, the need of a significant amount of construction work, resulting in heavy disturbance to the occupants [12]. For these reasons, their application is more feasible in new constructions, where the provision of the dissipative braces can be planned since the beginning, rather than for retrofit, because of architectural issues posed by the braces, like interference with the design of the façade and position of the openings [12]. Another issue concerns the fact that the design of dissipative bracing systems is performed respecting the "structural safety requirement" at the Ultimate Limit State only ([2],[10],[13]-[15]); indeed, the devices are designed not to be engaged under normal service loads and weak seismic excitations [12]. Consequently, under small earthquakes, a structure equipped with dissipative braces is subjected to greater accelerations than the bare configuration [5]. Moreover, tests carried out at the University of Basilicata (Italy) [16] have shown that the significant reduction of the frame lateral deformation, brought by the introduction of the hysteretic braces, is counteracted by a huge increase of Peak Floor Accelerations [5]. Similar results were obtained also from the numerical analyses performed by Gandelli et al. [17] on a hospital building equipped with dissipative bracing systems. This phenomenon has detrimental consequences especially to acceleration-sensitive non-structural components [5],[17]. In recent years, some researchers suggested using new kind of systems to control multi-levels of earthquake energy [6], to achieve stable deformation, increase structural ductility, and increase energy dissipation capacity with different stiffnesses [5], [18], [19] and [20].

Moreover, because of low-cycle fatigue and residual stresses of steel dampers, or large permanent deformations of friction and extrusion dampers, after a severe earthquake hysteretic dampers need to be replaced or restated, with consequent costs but also with a potential threat to the safety of the structure, which is left exposed to aftershocks which may occur in the aftermath of the main event.

In conclusion, a more robust form of energy dissipation is needed that satisfies several objectives [21]: (i) more compact and architecturally less invasive design in order to be ideally 
located within the beam-column joint region; (ii) should not require maintenance after a major earthquake, in order to guarantee a high safety level and maintain an economical appeal, especially for the retrofitting of conventional buildings; (iii) should not be at risk of low-cycle fatigue bar fracture; (iv) should ensure the re-centering of the structure; and (v) the cost of devices should be economical compared with conventional design solutions.

An emerging energy dissipation device likely to satisfy these conditions is the lead extrusion damper [22], [23], which dissipates energy through the plastic extrusion of lead, forced to flow through an annular restriction (Figure 1) provided either from a constriction of the tube (a), or a bulged shaft (b).

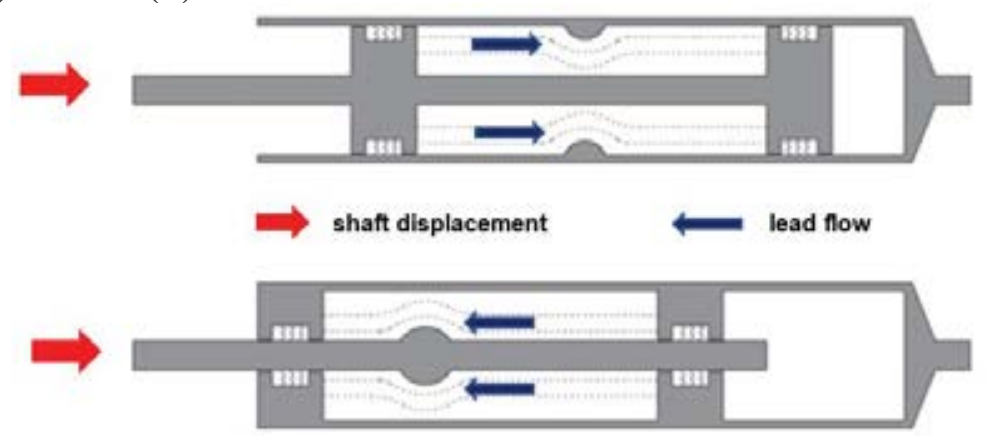

(a)

Figure 1: Longitudinal sections of lead extrusion damper: (a) constricted tube type; (b) bulged shaft type. Adapted from [24]

Two forces contribute to the overall output force of the device, namely the frictional resistance of the working material against the moving shaft, and the extrusion resistance of the lead that is forced to flow through the annular orifice [25], [26], making the device weakly dependent upon the velocity [27]. A part of the energy is immediately dissipated as heat, which induces softening of the working material and reduces its strength. However, the effect is temporary, because when the device is allowed to cool down, the original value of resistive force is recovered [26]. The other part of the energy is stored in the deformed lead which quickly recrystallizes and regains its original properties, resulting in consistent force across multiple cycles of response without any strain hardening or loss of strength or stiffness [23].

The main drawback of this device is the formation of voids within the working material during extrusion, which is attributed to compression of the lead: as the shaft moves, the material is compressed into a smaller volume leading to the formation of a trailing void [28], causing a decrease of the energy dissipation. For this reason, the lead extrusion dampers used in the first structural applications were quite large, in order to provide sufficient reaction force [22], [23]. Only in the first decade of the '21th century, Rodgers ([28], [29]) proposed an improved version called HF2V (High Force to Volume) where a substantial increase in the specific force was achieved by preloading the working material during the assembly. Increasing the internal pressure of the system reduced the formation of trailing voids and increased the reaction force and the force-to-volume ratio, allowing a more compact design. This device present an essentially rectangular hysteretic curve, which maximizes the amount of energy dissipation for a given applied force and displacement with a stable and repeatable behavior, an insignificant sensitivity to aging and environment, compact dimensions, and low cost [29][31].

The present study deals with the Prestressed Lead Extrusion Damper (P-LED), which achieves high specific output force by preloading of the working material [28]. The performance of the damper is assessed experimentally to verify the compliance to the requirements of the European standard [32]. Then, a finite element model is formulated and used to investigate the influence of the device dimensions on the output force. The numerical data points are 
fitted by a simple model which can be used for design of the damper to a specific quasi-static force.

\section{EPERIMENTAL INVESTIGATION}

\subsection{Description of the prototype}

A bulged-shaft type Prestressed Lead Extrusion Damper has been experimentally investigated in the study. The prototype has four main components, namely the bulged shaft, the tube, the cap and the working material (Figure 2). Tube, shaft and cap are made of structural steel, while the working material is $99.99 \%$ pure lead. The shaft is plated with hard chromium (70 $\mu \mathrm{m}$ thickness) in order to minimize friction and wear when sliding through the bushing provided in the cap. The cap is fixed to the tube wall by means of eight screws.

The characteristic dimensions of the device are: shaft diameter $D_{s}=32 \mathrm{~mm}$; bulge diameter $D_{\text {blg }}=42 \mathrm{~mm}$; inner diameter of the tube $D_{\text {cyl }}=60 \mathrm{~mm}$; length of shaft in contact with the working material $D_{s}=95 \mathrm{~mm}$. The design deflection is $d_{b d}=20 \mathrm{~mm}$ in either direction (i.e., $40 \mathrm{~mm}$ total stroke). To maintain the reaction aligned along the major axis of the device and avoid bending of the shaft, self-lubricating spherical hinges with a minimum rotation capacity of $\pm 2^{\circ}$ are provided at both ends of the damper, namely at one end of the shaft and on the bottom of the tube.

During the assembling process, the working material was prestressed to a nominal force of $280 \mathrm{kN}$ (corresponding to an average pressure of $138 \mathrm{MPa}$ on lead) by tightening the screws connecting the cap to the tube wall. Pre-stressing the working material was aimed at increasing the friction between the tube and the shaft and preventing coring out of the lead as the bulge is forced through.

Three thermocouples were inserted into $\varnothing 5 \mathrm{~mm}$ blind holes drilled in the lateral wall of the containing tube, about $5 \mathrm{~mm}$ away from the chamber filled with the working material, in order to measure the temperature, rise during the extrusion process.

a)

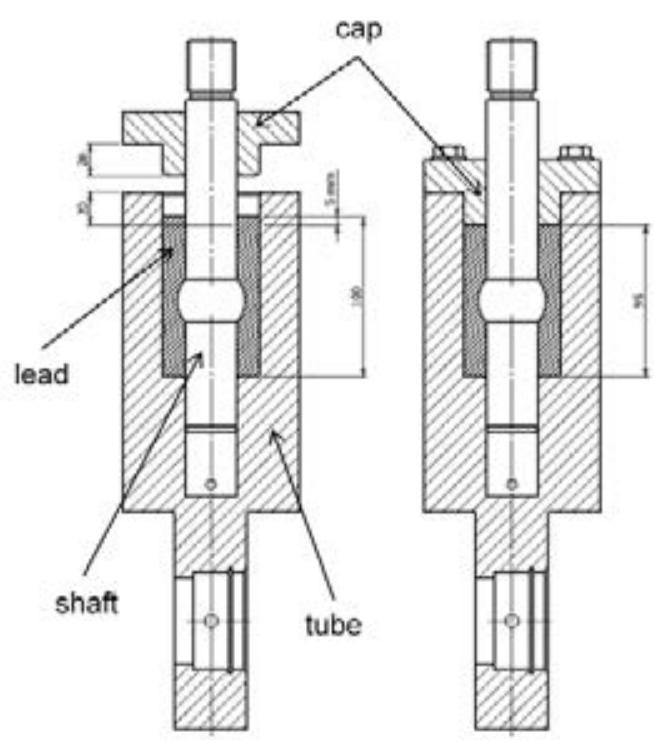

b)

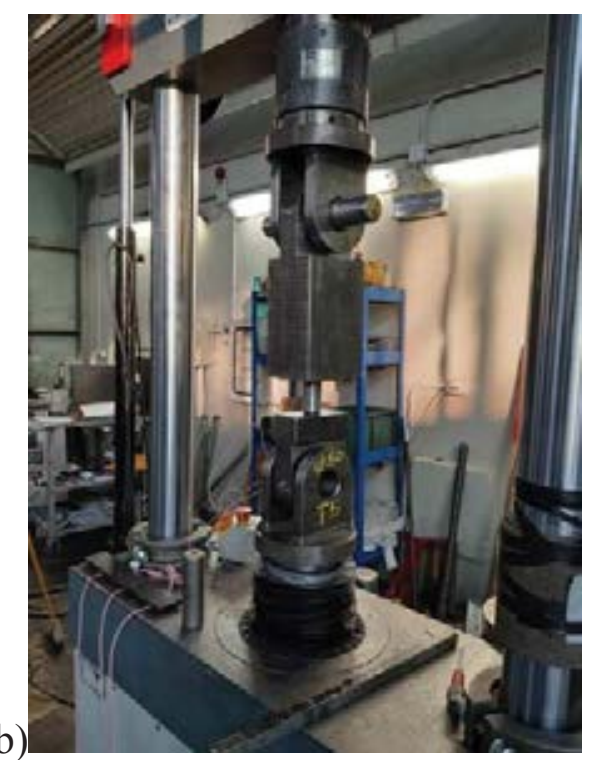

Figure 2: (a) Cross-section of the bulged-shaft P-LED; (b) prototype on the testing machine

\subsection{Experimental procedure}

The experiments were performed at the Materials Testing Laboratory of Politecnico di Milano, using a $500 \mathrm{kN}$ servohydraulic testing machine (MTS Systems, Eden Prairie, MN). 
The specimen was subjected to the type testing protocol prescribed in the European standard EN 15129 [32] for assessment of Displacement Dependent Devices, i.e. damping systems whose reaction force depends essentially on the displacement. The hysteretic force-deflection response was evaluated by imposing harmonic cycles of increasing amplitude at $25 \%, 50 \%$ and $100 \%$ of the design deflection $\mathrm{d}_{\mathrm{bd}}=20 \mathrm{~mm}$, at a loading frequency of $0.5 \mathrm{~Hz}$. Five cycles for each intermediate amplitude and ten cycles for the maximum amplitude were applied. Eventually, a ramp test at $0.1 \mathrm{~mm} / \mathrm{s}$ rate was performed to the amplified design displacement $\gamma_{\mathrm{b}} \gamma_{\mathrm{x}} \mathrm{d}_{\mathrm{bd}}=26.4 \mathrm{~mm}$ (where $\gamma_{\mathrm{b}}=1.1$ and $\gamma_{\mathrm{x}}=1.2$ are the amplification factor and the reliability factor given in the standard, respectively), to assess the failure condition under quasi-static condition.

It is here noted that according to the standard the type tests performed on one specimen of a device can be deemed valid also for new models of the device with same geometry, working materials and constraints, provided that the geometrical linear differences between the new and the tested model are less than $20 \%$ and the results can be suitably extrapolated to the new device.

In order to assess the recovery of the original output force after cooling of the working material, at the end of the experimental protocol requested by the standard the prototype was left at rest for 45 minutes and then subjected to a second series of 10 cycles to $d_{b d}$..

\section{RESULTS AND DISCUSSION}

The force-displacement behavior of the P-LED prototype at the design deflection $\mathrm{d}_{\mathrm{bd}}=20$ $\mathrm{mm}$ is shown in Figure 3: in Figure 3(a) the prototype is subjected to the preload of $280 \mathrm{kN}$ to prestress the lead, while in Figure 3(b), the prototype was tested without application of the preload. The hysteresis loops in Figure 3(a) have an almost rectangular shape, but for some "cut-outs" at motion reversals which are attributed to a small trailing void, that occurred in the lead in spite of the initial prestress. However, after the cut-out, the force achieves an essentially constant level, thus maximizing the amount of energy dissipation. From the shape of the hysteresis loop the length of the trailing void created behind the bulge is estimated to be approximately $9 \mathrm{~mm}$ over a total stroke of $40 \mathrm{~mm}$. In Figure 3(b), the size of the trailing void increases to about $23 \mathrm{~mm}$, significantly reducing the dissipated energy; also the output force is substantially smaller than in the previous case (e.g., $187 \mathrm{kN}$ vs. $228 \mathrm{kN}$ at the third cycle) due to the lower confinement of lead and the decrease in the extrusion resistance.
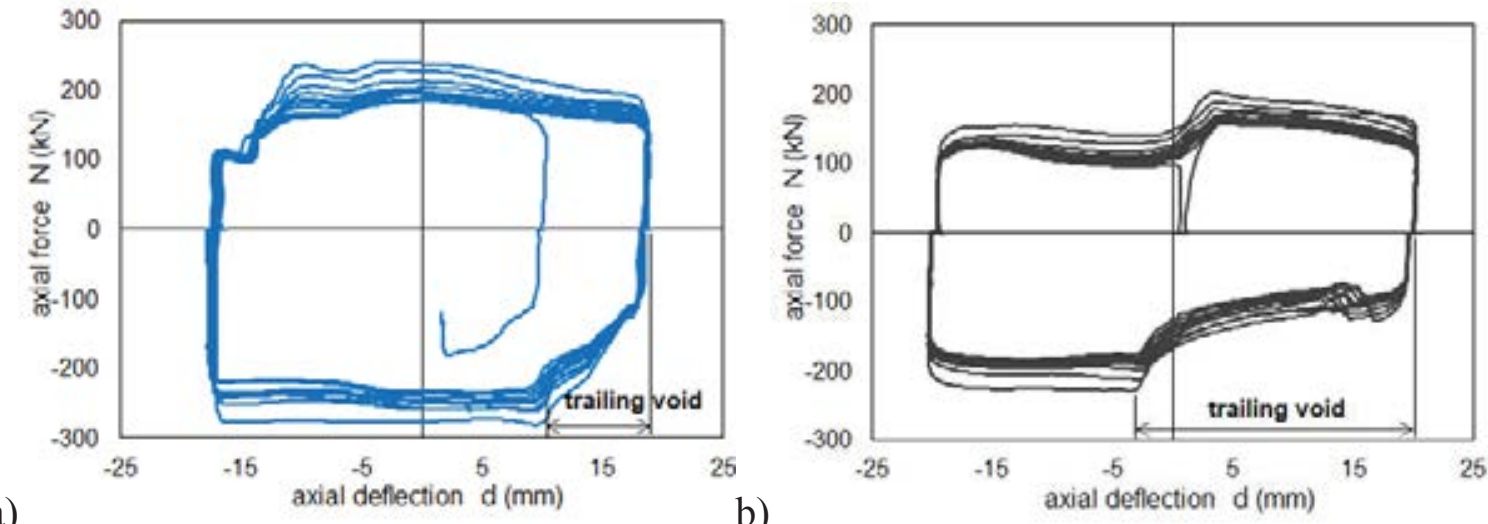

a)

Figure 3: (a) Hysteresis loops of the P-LED prototype preloaded at $280 \mathrm{kN}$ and tested to the design deflection $d_{b d}=20 \mathrm{~mm}$; (b) hysteresis loops of the prototype without prestressing

The strength of the device declines as the number of cycles proceeds due to heating of lead (Figure 4); the output force $\mathrm{N}_{\mathrm{b}}$ (evaluated as the average force on each branch, after the cutout) shrinks from $205 \mathrm{kN}$ at the first cycle to $170 \mathrm{kN}$ at the tenth cycle in extension, and from $243 \mathrm{kN}$ to $193 \mathrm{kN}$ in compression. The largest decrease occurs between the first and the third 
cycle $(-13 \%)$, and then the force tends to approach a steady value. It must be here recalled that the temperature reported in the panel in Figure 4 was measured in the steel wall of the tube, about $5 \mathrm{~mm}$ away from the lead, and therefore underestimates the actual temperature of the working material.

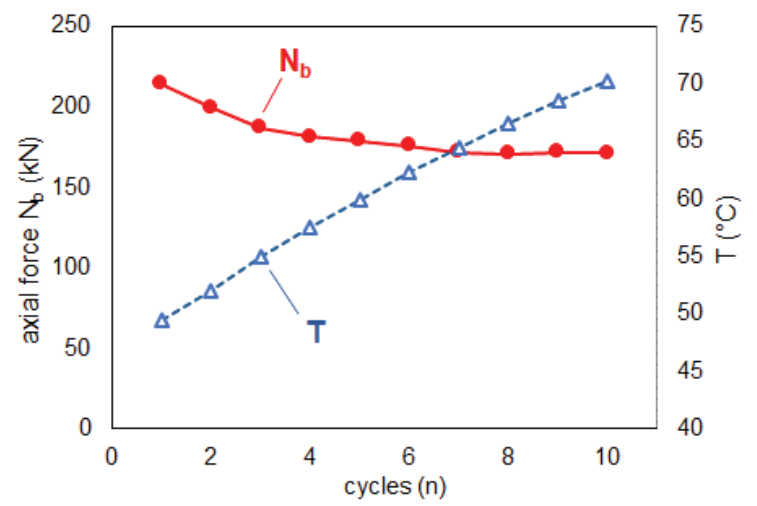

Figure 4: Progress of output force (mean value between extension and compression) and temperature within the tube wall vs. number of cycles

Two quantities are calculated at each cycle and used to characterize the response of the PLED, namely the effective stiffness $\mathrm{K}_{\mathrm{eff}}=\mathrm{N}_{\mathrm{b}} / \mathrm{d}_{\mathrm{b}}$ and the effective damping $\xi_{\text {eff }}=2 \mathrm{~A}_{\text {cycle }} /\left(\pi 4 \mathrm{~K}_{\mathrm{eff}} \mathrm{d}_{\mathrm{b}}\right)$, where $\mathrm{N}_{\mathrm{b}}$ is the output force of the prototype, $\mathrm{d}_{\mathrm{b}}$ is the maximum cycle deflection and $A_{\text {cycle }}$ is the area of the hysteresis loop.

The European standard [32] requires that both $K_{\text {eff }}$ and $\xi_{\text {eff }}$ remain essentially constant as the cycles proceed $\left(^{(a)}\right.$ subscript 3 is relevant to quantities assessed at the third load cycle, and subscript $i$ is relevant to quantities at the $i$-th cycle, excluding the first cycle $(i \geq 2)$

Table 1); in particular, except for the first cycle, the difference among the cycles must remain within the $10 \%$.

\begin{tabular}{cccc}
\hline & \multicolumn{3}{c}{ Test results } \\
\cline { 2 - 4 } Requirement $^{(\mathrm{a})}$ & $\mathrm{d}_{\mathrm{b}}=5 \mathrm{~mm}$ & $\mathrm{~d}_{\mathrm{b}}=10 \mathrm{~mm}$ & $\mathrm{~d}_{\mathrm{b}}=20 \mathrm{~mm}$ \\
\hline $\mathrm{K}_{\mathrm{eff}, \mathrm{i}}-\mathrm{K}_{\mathrm{eff}, 3} \mid / \mathrm{K}_{\mathrm{eff}, 3}<0.10$ & 0.024 & 0.035 & 0.098 \\
$\left|\xi_{\text {eff,i }}-\xi_{\text {eff, } 3}\right| / \xi_{\mathrm{eff}, 3}<0.10$ & 0.012 & 0.046 & 0.024
\end{tabular}

(a) subscript 3 is relevant to quantities assessed at the third load cycle, and subscript i is relevant to quantities at the $i$-th cycle, excluding the first cycle $(i \geq 2)$

Table 1: Stability requirements for Non Linear devices [32] and results of the tests on the P-LED prototype

The average value of $\xi_{\text {eff }}$ evaluated over 10 cycles performed at the design deflection is 0.55 , i.e. $86 \%$ of the effective damping of an ideally rectangular loop, confirming the good dissipation capacity of the P-LED. After cooling lead recrystallizes and recovers its original properties, thereby providing a reliable and consistent response even in case of multiple loading sequences occurring within short time: after the execution of the experimental program prescribed by the standard, the prototype was left at ambient temperature for 45 minutes and then subjected to a second sequence of cycles at $\mathrm{d}_{\mathrm{bd}}$; the stiffness and damping were practically unchanged from the previous sequence, with a $-4 \%$ difference on $\mathrm{K}_{\text {eff }}$ and $0 \%$ on $\xi_{\text {eff }}$ at the third cycle (curves labelled as " $\mathrm{d}_{\mathrm{b}}=20 \mathrm{~mm}$ (2)" in Figure 5). 

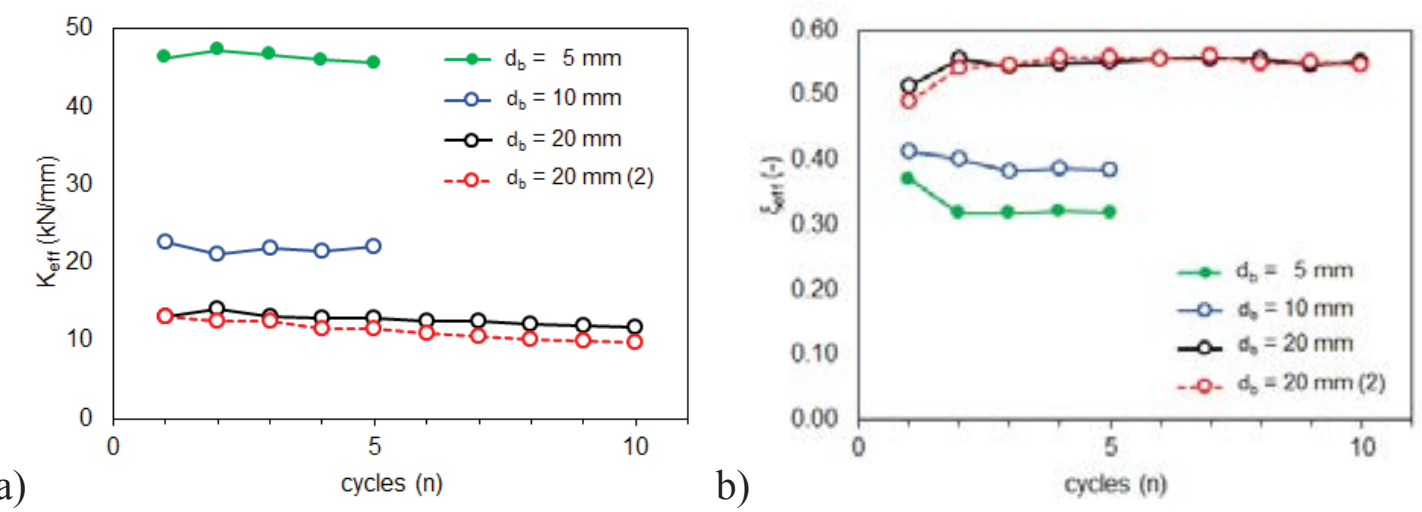

Figure 5: Plots of (a) effective stiffness $K_{\text {eff, }}$ and (b) effective damping $\xi_{\text {eff }}$ of the P-LED vs. number of cycles at different deflection amplitudes $\mathrm{d}_{\mathrm{b}}$

Eventually, in the monotonic ramp test (Figure 6) the prototype was able to sustain the amplified design deflection $\gamma_{\mathrm{x}} \gamma_{\mathrm{b}} \mathrm{d}_{\mathrm{bd}}$ without leakage of working material. The force-deflection curves presents an initial peak which is ascribed to the transition from the static to the kinetic friction between lead and shaft [26] and then stabilizes at a constant level, demonstrating the ability to accommodate the prescribed displacement without any damage or deterioration of stiffness.

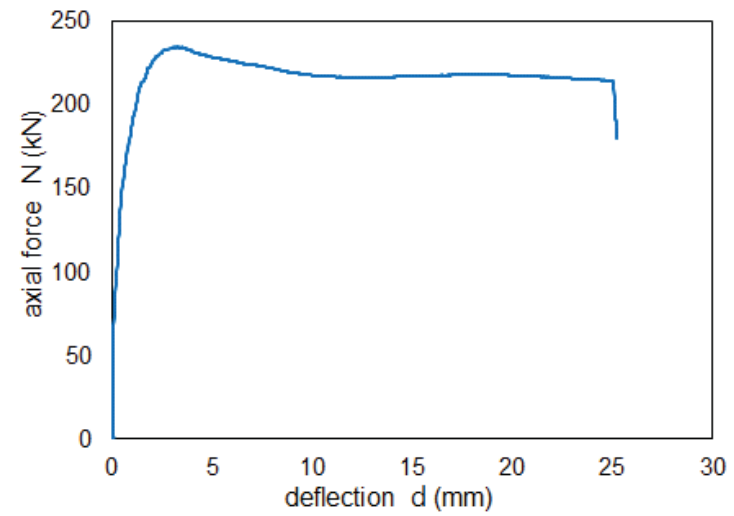

Figure 6: Force-deflection relationship of P-LED under quasi-static condition

\section{NUMERICA INVESTIGATION}

\subsection{FE model}

A 3D finite element model of the prototype presented in Section 2 was formulated in the general-purpose software Abaqus/CAE 6.14-2 [33], using 4-node bilinear axisymmetric elements type C4X4. By exploiting the symmetry of the system about its longitudinal axis, only half of the prototype is modelled.

The model includes four parts: the shaft, the tube, the plug and the working material (Figure 7). The region of the working material is meshed with fine mesh (maximum size $3.3 \mathrm{~mm}$ ) along the shaft region where large deformation is expected, in order to allow realistic simulation of lead flow around the shaft (Figure 7(b)), without severe distortion of the elements, which may cause abortion of analysis. 


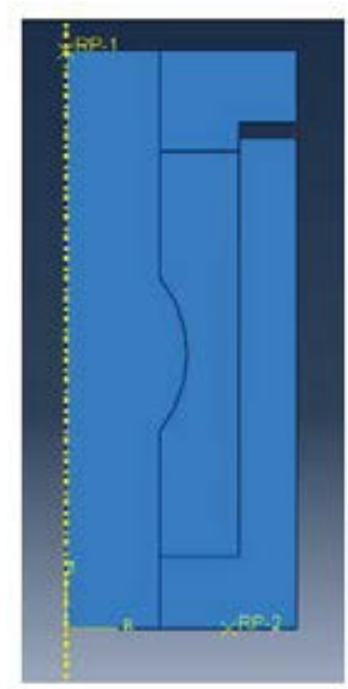

(a)

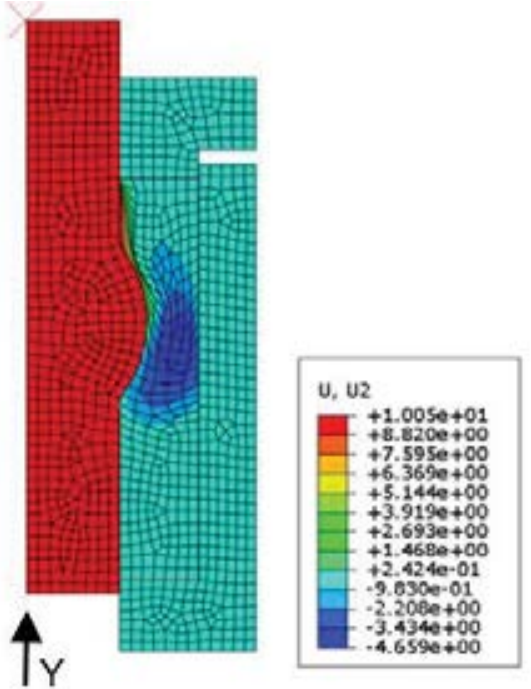

(b)

Figure 7: (a) Physical model of P-LED; (b) lead flow through the orifice between bulge and containing tube during motion of the shaft (U2: displacement in Y direction, unit: $\mathbf{m m}$ )

Lead is modelled as an elastic-almost perfectly plastic material (a small hardening is introduced in order to avoid convergence issues), and S450 steel is assumed for shaft, tube and cap regions. The modelling parameters of the FE model are as tabulated in Table 2 [34]. Hard contact is introduced at the interface between shaft and tube and between shaft and cap, while hard contact in normal direction, and frictional behavior in shear direction is assumed at the interfaces between lead and shaft and between lead and containing tube, where the coefficient of friction counts $\mu=0.15$ and $\mu=0.30$ respectively. The analyses are performed in two steps. In the first step, prestressing of the working material is simulated by applying a constant force of $280 \mathrm{kN}$ uniformly distributed on the upper surface of the cap, pressing the cap on the lead. In the second step, dynamic implicit analysis is performed by imposing a cyclic displacement history to the shaft. Three analyses are conducted, with displacement amplitude of $5 \mathrm{~mm}, 10$ $\mathrm{mm}$ and $20 \mathrm{~mm}$, respectively.

\begin{tabular}{|c|c|c|c|}
\hline Properties & Steel & \multicolumn{2}{|c|}{ Lead } \\
\hline $\mathrm{E}[\mathrm{GPa}]$ & 210 & \multicolumn{2}{|c|}{16.4} \\
\hline$v[-]$ & 0.33 & \multicolumn{2}{|c|}{0.44} \\
\hline$\rho\left[\mathrm{kg} / \mathrm{mm}^{3}\right]$ & $7.85 \times 10^{-6}$ & \multicolumn{2}{|c|}{$8 \times 10^{-6}$} \\
\hline \multirow{6}{*}{ Plastic behavior } & Plastic Strain Stress [MPa] & \multicolumn{2}{|c|}{ Plastic Strain Stress [MPa] } \\
\hline & $\begin{array}{ll}0 & 450\end{array}$ & 0 & 20.5 \\
\hline & \multirow{4}{*}{0.2} & 0.001 & 21.5 \\
\hline & & 0.002 & 22.0 \\
\hline & & 0.1 & 22.5 \\
\hline & & 0.3 & 23.0 \\
\hline
\end{tabular}

$E=$ Young's Modulus [GPa], $v=$ Poisson's Ratio [-], $\rho=$ density $\left[\mathrm{kg} / \mathrm{mm}^{3}\right]$

Table 2: Material properties used in the FE model

The quasi-static output force vs. deflection curves calculated from the model are compared to the experimental curves evaluated at the third cycle of each test. The agreement between model and experimental data is good in the first and in the third quadrant of the diagram, but some deviation is observed at motion reversals (Figure 8). This is due to the fact that the numerical model does not account for trailing void, i.e. no gap can occur between working material and shaft as the bulge passes through the lead. 


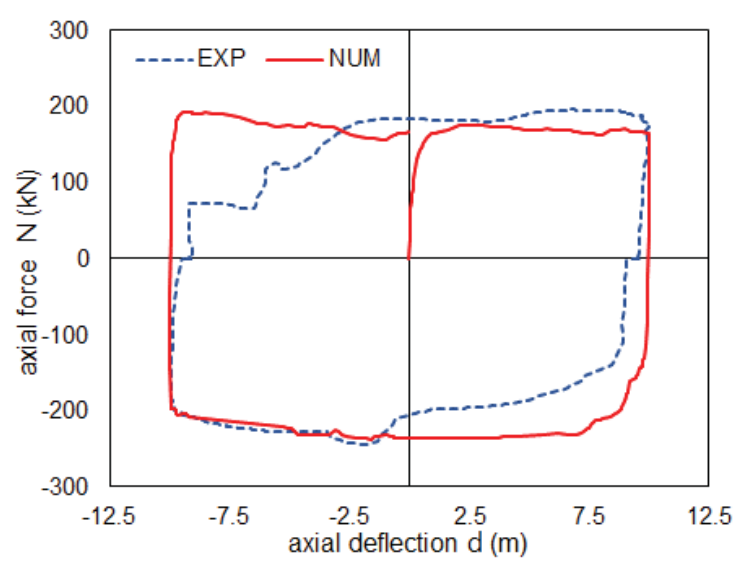

Figure 8: Comparison between calculated (NUM) and experimental (EXP) hysteresis loop

\subsection{Effect of device dimensions}

The numerical model is then applied to investigate combinations of a wide range of device dimensions (Table 3), to enable device optimization and further delineate the contributions of friction and extrusion forces to the overall reaction force produced by the device. In each analysis the compressive force on the lead is adjusted to the actual cross-section of the working material in order to provide an average pressure of $138 \mathrm{MPa}$.

$$
\begin{array}{cc}
\hline \text { Dimensions }[\mathrm{mm}] & \text { Values } \\
\hline \mathrm{D}_{\mathrm{s}} & 32-34-36 \\
\mathrm{D}_{\mathrm{blg}} & 33-34-35-37-38-40-42-44-46 \\
\mathrm{D}_{\mathrm{cyl}} & 50-55-60-70 \\
\mathrm{~L}_{\mathrm{s}} & 75-95-115 \\
D_{s}=\begin{array}{c}
\text { Shaft diameter, } D_{\text {blg }}=\text { Bulge diameter, } D_{\text {cyl }}=\text { tube diameter, } L_{s}=\text { shaft length } \\
\text { Table 3: Device dimensions investigated in the study }
\end{array}
\end{array}
$$

The importance of either force contribution can be appreciated in Figure 9(a), where the first data point of each plot represents the situation where the extrusion force is negligible $\left(\mathrm{D}_{\mathrm{blg}} \approx\right.$ $\mathrm{D}_{\mathrm{s}}$ ), and the output force is essentially provided by the frictional resistance of the prestressed lead on the lateral surface of the moving shaft (the relative velocity on the tube surface is almost null); a larger shaft diameter corresponds to a larger contact area and hence a larger frictional force. In contrast, increasing the bulge diameter $\mathrm{D}_{\text {blg }}$ reduces the area of the annular orifice through which lead flows, and thereby increases the extrusion resistance; this contribution is independent of $\mathrm{D}_{\mathrm{s}}$ and becomes more important as $\mathrm{D}_{\text {blg }}$ approaches $\mathrm{D}_{\text {cyl. }}$. It is worth noting that only for large values of $D_{b l g}$, i.e. $D_{b l g}>44 \mathrm{~mm}$, the contribution from extrusion becomes equal to, or larger than, the frictional resistance. A similar conclusion (i.e. the friction force is a large part of the overall response) was reported in previous studies which compared the response of bulged, constrained and straight (i.e. without bulge) shafts [25], [27].

Figure 9(b), 9(c) and 9(d) show the effect of the tube diameter. When $D_{b l g}$ is small in comparison to $\mathrm{D}_{\text {cyl }}\left(\mathrm{D}_{\text {blg }} / \mathrm{D}_{\text {cyl }} \leqslant 0.8\right)$, the output force is not influenced by the diameter of the tube; in contrast when the gap is small (less than $4 \mathrm{~mm}$ in the examined cases) the extrusion resistance has a steep increase, inducing large forces that can eventually lead to structural failure of the rod or the cap screws. 


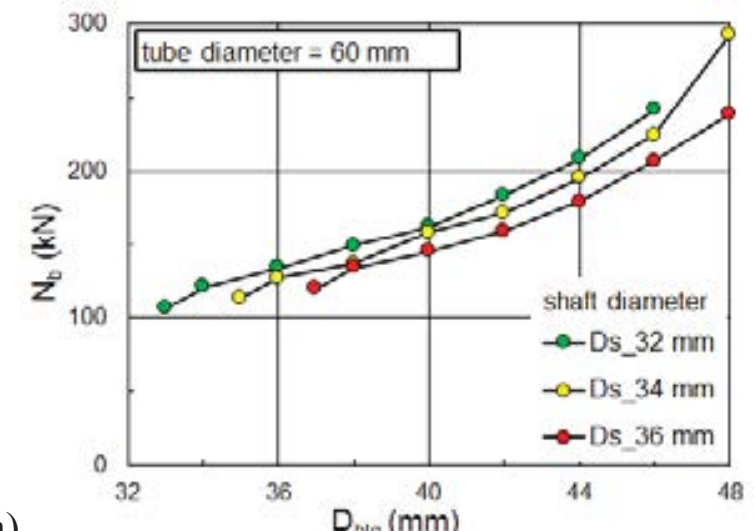

a)

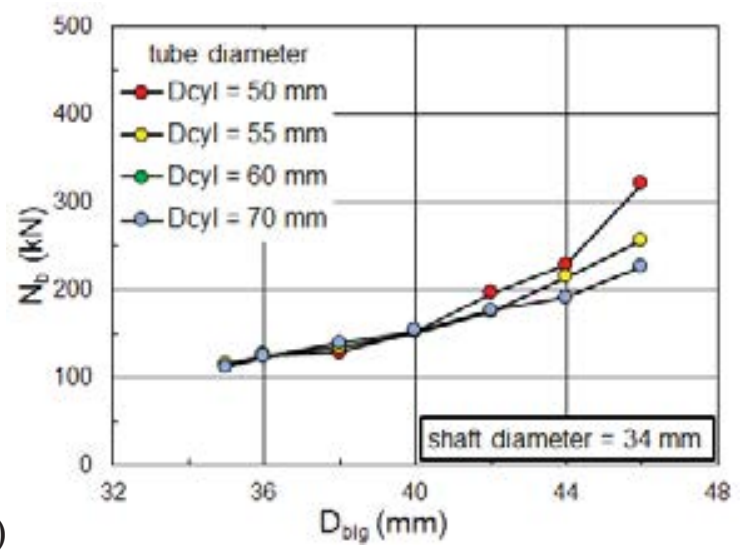

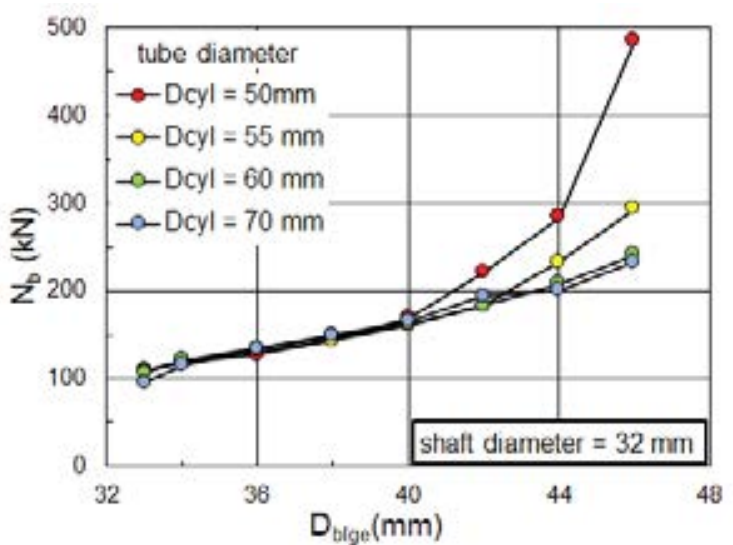

b)

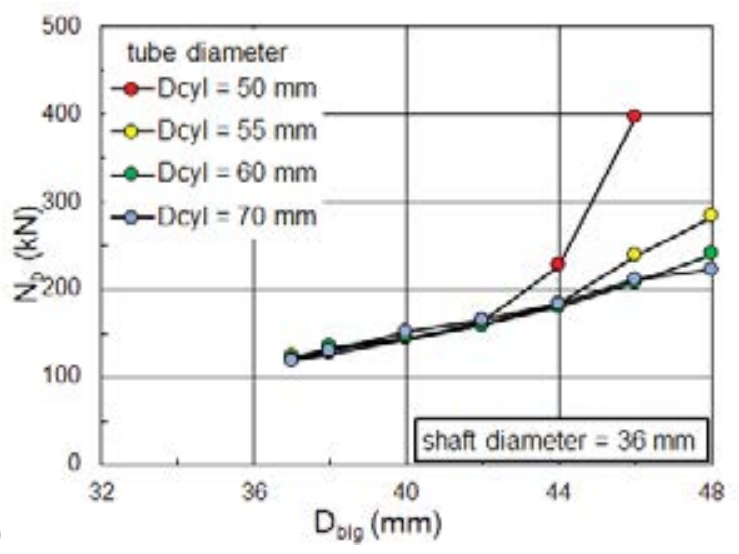

Figure 9: Influence of device dimensions of P-LED on the quasi-static output force $\mathrm{N}_{\mathrm{b}}$ : (a) influence of shaft diameter $D_{s}$ and bulge diameter $D_{\text {blg }}$ for assigned tube diameter $D_{\text {cyl }}=60 \mathrm{~mm}$ and shaft length $L_{s}=$ $95 \mathrm{~mm}$; (b) (c) (d) influence of tube diameter $D_{\mathrm{cyl}}$ and bulge diameter $D_{\text {blg }}$ for assigned shaft diameter $D_{s}=$ $32 \mathrm{~mm}, D_{\mathrm{s}}=34 \mathrm{~mm}$, and $D_{\mathrm{s}}=36 \mathrm{~mm}$, respectively

\section{CONCLUSIONS}

The study investigated the behavior of an emerging energy dissipation device, namely Prestressed Lead Extrusion Damper (P-LED. The device provides energy dissipation through the plastic extrusion of lead through an orifice created between a containing tube and a bulged shaft, and achieves high specific output force though preloading of the working material during the assembly.

A prototype of the P-LED was experimentally assessed according to the provisions of the European standard EN 15129 [32] for displacement dependent devices. The damper exhibits a consistent rigid-plastic behavior without strength degradation regardless of the imposed displacement up to the amplified deflection prescribed by the standard. The influence of the rate of deflection is weak over the tested range and can be ignored from a practical point. Cyclic tests were used to evaluate the response of the damper at different displacement amplitudes. Neglecting the effects of trailing voids at motion reversals, the hysteresis loops have an essentially rectangular shape with an equivalent damping ratio of 0.55 , close to the maximum theoretical value of 0.63 .

The tested specimen is able to sustain multiple sequences of motion at the basic design earthquake displacement, demonstrating its ability to provide maintenance-free operation even in presence of repeated ground shakes. Though a certain softening of the working material is observed due to heating, the changes in stiffness and damping capacity over 10 cycles at the design deflection lie within the $\pm 10 \%$ bound. Besides, the effect of heating is only tem- 
porary, and when the damper is cooled down to ambient temperature, the stiffness and damping characteristics return to their original value.

A 3D finite element model of the P-LED device was formulated and validated against the experimental data. The numerical formulation was then used, in a parametric study, to investigate the effect of the device dimensions on the output force. The main parameters determining the response of the P-LED are found to be the annular area of lead around shaft and the projected area of the bulge, which are related to the extrusion force of the working material, and the area of the lateral surface of the shaft, which is proportional to the fiction force arising from the relative motion between shaft and lead. 


\section{REFERENCES}

[1] A. Di Cesare, F. C. Ponzo, D. Nigro. Assessment of the performance of hysteretic energy dissipation bracing systems. Bulletin of Earthquake Engineering, 12(6), 2777-2796, 2014; DOI: 10.1007/s10518-014-9623-z.

[2] A. Di Cesare, F. C. Ponzo. Seismic retrofit of reinforced concrete frame buildings with hysteretic bracing systems: design procedure and behaviour factor. Hindawi, Shock and Vibration, Volume 2017, Article ID 2639361, DOI: 10.1155/2017/2639361.

[3] F. Aliakbari, S. Garivani, A.A. Aghakouchak. An energy based method for seismic design of frame structures equipped with metallic yielding dampers considering uniform inter-story drift concept, Engineering Structures 2020, 205, 110114 , https://doi.org/10.1016/j.engstruct.2019.110114.

[4] S. Garivani, S.S. Askariani, A.A. Aghakouchak. A.A. Seismic design of structures with yielding dampers based on drift demands, Structures 2020, 28, 1885-1899, https://doi.org/10.1016/j.istruc.2020.10.019.

[5] E. Gandelli, S. Chernyshov, J. Distl, P. Dubini, F. Weberd, A. Taras. Novel adaptive hysteretic damper for enhanced seismic protection of braced buildings, Soil Dynamics and Earthquake Engineering 2021, 141, 106522, https://doi.org/10.1016/j.soildyn.2020.106522.

[6] M.Z. Golmoghany, S.M. Zahrai. Improving seismic behavior using a hybrid control system of friction damper and vertical shear panel in series, Structures 2021, 31, 369-379, https://doi.org/10.1016/j.istruc.2021.02.007.

[7] C. Christopolous, A. Filiatrault. Principles of passive supplemental damping and seismic isolation. IUSS Press 2006, Pavia.

[8] C. Durucan, M. Dicleil. Analytical study on seismic retrofitting of reinforced concrete buildings using steel braces with shear link, Engineering Structures 2010, 32, 29953010, doi:10.1016/j.engstruct.2010.05.019.

[9] F. Mazza, A. Vulcano. Equivalent viscous damping for displacement-based seismic design of hysteretic damped braces for retrofitting framed buildings, Bulletin of Earthquake Engineering 2014, 12, pages2797-2819, DOI 10.1007/s10518-014-9601-5.

[10] F. Mazza, A. Vulcano. Displacement-based design procedure of damped braces for the seismic retrofitting of r.c. framed buildings, Bulletin of Earthquake Engineering 2015, 12:2121-2143, DOI 10.1007/s10518-014-9709-7.

[11] F. Yang, G. Wang, M. Li. Evaluation of the Seismic Retrofitting of MainshockDamaged Reinforced Concrete Frame Structure Using Steel Braces with Soft Steel Dampers. Applied Science 2021, 11, 841. https://doi.org/10.3390/app11020841.

[12] J.E. Martínez-Rueda. On the evolution of energy dissipation devices for seismic design, Earthquake Spectra 2002, Volume 18, Issue 2, Pages 309-346.

[13] CSLLPP (Consiglio Superiore dei Lavori Pubblici). Circolare 21 gennaio 2019, n. 7 C.S.LL.PP. Istruzioni per l'applicazione dell' «Aggiornamento delle "Norme tecniche per le costruzioni"» di cui al decreto ministeriale 17 gennaio 2018, Roma; 2019, in Italian. 
[14] F. Braga, F. Buttarazzi, A. Dell'Asta, W. Salvatore. Protezione sismica di edifici in c.a. con controventi dissipativi in acciaio. Dario Flaccovio Editore 2015; (in Italian).

[15] G. Lomiento, N. Bonessio, F. Braga. Design criteria for added dampers and supporting braces. Seismic Isolation and Protection Systems 2010, 1(1):55-73.

[16] F.C. Ponzo, A. Di Cesare, N. Lamarucciola, D. Nigro. Seismic design and testing of post-tensioned timber buildings with dissipative bracing systems. Frontiers in Built Environment 2019, 5(104). https://doi.org/10.3389/fbuil.2019.00104.

[17] E. Gandelli, A. Taras, J. Disti, V. Quaglini. Seismic retrofit of hospitals by means of hysteretic braces: influence on acceleration-sensitive non-structural components. Frontiers in Built Environment 2019, 5(100), DOI: doi.org/10.3389/fbuil.2019.00100.

[18] Z. Li, H. Dong, X. Wang, M. He. Experimental and numerical investigations into seismic performance of timber-steel hybrid structure with supplemental dampers, Engineering Structures 2017, 151, pp. 33-43, 10.1016/j.engstruct.2017.08.011.

[19] A. Naeem, J. Kim J. Seismic performance evaluation of a multi-slit damper, Engineering Structures 2019, 189, pp. 332-346, 10.1016/j.engstruct.2019.03.107.

[20] T. Balendra, C.H. Yu, F.L. Lee. An economical structural system for wind and earthquake loads. Engineering Structures 2001, 23:491-501. https://doi.org/10.1016/S01410296(00)00061-4.

[21] G.W. Rodgers, K.M. Solberg, J.G. Chase, J.B. Mander, B.A. Bradley, R.P. Dhakal, L. Li. Performance of a damage-protected beam-column subassembly utilizing external HF2V energy dissipation devices. Earthquake Engineering and Structural Dynamics 2008b, 37(13): 1549-1564, DOI: 10.1002/eqe.830.

[22] W.H. Robinson, L.R. Greenbank. Properties of an extrusion energy absorber. Bulletin of the New Zealand National Society for Earthquake Engineering 1975, 8(3), 187-191.

[23] W.H. Robinson, L.R. Greenbank. An extrusion energy absorber suitable for the protection of structures during an earthquake. Earthquake Engineering \& Structural Dynamics 1976, 4(3), 251-259, DOI: 10.1002/eqe.4290040306.

[24] W.J. Cousins, T.E. Porrit. Improvements to lead-extrusion damper technology. Bulletin of the New Zealand National Society for Earthquake Engineering 1993, 26, 342-348.

[25] V. Vishnupriya, G.W. Rodgers, J.B. Mander, J.G. Chase. Precision design modelling of HF2V devices. Structures 2018, 14, 243-250, DOI: 10.1016/j.istruc.2018.03.007.

[26] G.W. Rodgers, J.G. Chase, J.B. Mander, J.B. Repeatability and high-speed validation of supplemental lead-extrusion energy dissipation devices. Advances in Civil Engineering 2019, Article ID 7935026, DOI: 10.1155/2019/7935026.

[27] J.C. Golodrino, J.G. Chase, G.W. Rodgers, G.A. MacRae, C.G. Clifton. Velocity dependence of HF2V devices using different shaft configurations. Annual Conference of the New Zealand Society for Earthquake Engineering 2012, Christchurch, New Zealand, paper 99.

[28] G.W. Rodgers, J.G. Chase, J.B. Mander, N.C. Leach, C.S. Denmead. Experimental development, tradeoff analysis and design implementation of high force-to-volume damping technology. Bulletin of the New Zealand National Society for Earthquake Engineering 2007a, 40(2), 35-48. 
[29] G.W. Rodgers, J.B. Mander, JG. Chase, R.P. Dhakal, N.C. Leach, C.S. Denmead. Spectral analysis and design approach for high force-to-volume extrusion damper-based structural energy dissipation. Earthquake Engineering and Structural Dynamics 2008a, 37(2), 207-223, DOI: 10.1002/eqe.752.

[30] G.W. Rodgers, J.G. Chase. Testing of Lead Extrusion Damping devices undergoing representative earthquake velocities. Annual Conference of the New Zealand Society for Earthquake Engineering 2013, Wellington, New Zealand.

[31] D.A. Latham, A.M. Reay, S. Pampanin. Kilmore Street Medical Centre: application of an advanced flag-shape steel rocking system. Annual Conference of the New Zealand Society for Earthquake Engineering 2013, Wellington, New Zealand.

[32] CEN, European Committee for Standardization (2009). EN 15129. Anti-seismic devices. Brussels.

[33] Dassault Systemes Simulia Corp. (2017). Abaqus/CAE user's guide, Providence.

[34] V. Vishnupriya, G.W. Rodgers, J.G. Chase. Finite Element Modelling of HF2V lead extrusion dampers for specific force capacities. Procedure of the Pacific Conference on Earthquake Engineering and Annual Conference of the New Zealand Society for Earthquake Engineering 2019, Auckland, New Zealand, paper 133. 